\title{
Evaluation of the independent and combined effects of xylitol and polydextrose consumed as a snack on hunger and energy intake over $10 \mathrm{~d}$
}

\author{
Neil A. King ${ }^{1 *}$, Stuart A. S. Craig ${ }^{2}$, Tammy Pepper ${ }^{2}$ and John E. Blundell ${ }^{1}$ \\ ${ }^{1}$ BioPsychology Group, Institute of Psychological Sciences, University of Leeds, Leeds LS2 9JT, UK \\ ${ }^{2}$ Danisco Inc., Ardsley, NY 10 502, USA
}

(Received 3 February 2004 - Revised 7 January 2005 - Accepted 17 January 2005)

\begin{abstract}
The study assessed the independent and combined effect of two speciality carbohydrates (polydextrose and xylitol) on appetite. Eight female and seven male lean volunteers were recruited from the University of Leeds campus. Using a repeated measures design, volunteers completed four conditions in a counterbalanced order. Each condition varied according to the yoghurt formulation administered: a control yoghurt (C, yoghurt $+25 \mathrm{~g}$ sucrose) and three experimental yoghurts $(\mathrm{X}$, yoghurt $+25 \mathrm{~g}$ xylitol; $\mathrm{P}$, yoghurt $+25 \mathrm{~g}$ polydextrose; and $\mathrm{XP}$, yoghurt $+12 \cdot 5 \mathrm{~g}$ xylitol and $12 \cdot 5 \mathrm{~g}$ polydextrose $)$. Each condition lasted for $10 \mathrm{~d}$ during which volunteers consumed $200 \mathrm{~g}$ yoghurt on each day. On days 1 and 10, the short- and medium-term effects of yoghurt consumption were assessed by measuring ad libitum lunch intake and subjective motivation to eat. The three experimental yoghurts (X, P and XP) induced a slight suppression of energy intake compared with the control (C) yoghurt, but the differences were not statistically significant. However, when the energy content of the yoghurt pre-loads were accounted for, there was a significant suppression of energy intake for $\mathrm{P}$ compared with $\mathrm{C}(P=0 \cdot 002)$. The $\mathrm{XP}$ yoghurt induced a significantly stronger satiating effect (increase in subjective fullness) compared with $\mathrm{C}$, both with $(P=0 \cdot 003)$ and without $(P<0 \cdot 001)$ the differential in energy content of the yoghurt pre-loads accounted for. The study demonstrated that pre-loads of xylitol and polydextrose caused a mild increase in satiety and suppression of energy intake, and that the effects persist after repeated daily administration. The effects exerted by the formulations containing xylitol and polydextrose did not arise from the differences in energy content of the yoghurt per se. Therefore, the usefulness of xylitol and polydextrose as ingredients in functional foods for appetite control are as a result of their lower energy content and suppression of appetite.
\end{abstract}

Xylitol: Polydextrose: Sweeteners: Appetite

There is currently considerable interest in the role of functional foods for appetite control. In principle, such foods could exert effects via two routes: by reducing the energy value of the food consumed or by stimulating satiety signalling systems. Some food materials could act through both routes simultaneously. Low-energy ingredients have been used as substitutes for carbohydrates (e.g. polyols and artificial sweeteners) and fats (e.g. sucrose polyester) in an attempt to reduce total energy intake. Xylitol is a monosaccharide polyol that is used in a variety of foods, and is commonly found in chewing gum and confectionery. Xylitol yields $40 \%$ less energy than sugar, as it is not fully absorbed in the intestine. The remaining unabsorbed material passes to the lower gut where it is subject to microbial fermentation. Consequently, the substitution of xylitol for sugars could lower the energy value of food. However, studies have shown that xylitol delays gastric emptying (Shafer et al. 1987; Salminen et al. 1989), suggesting that xylitol could influence food intake through this mechanism. Previous studies examining the effect of xylitol on gastric emptying have used $5-25 \mathrm{~g} / \mathrm{d}$ (Shafer et al. 1987 ) and $30 \mathrm{~g} / \mathrm{d}$ (Salminen et al. 1989). In contrast to xylitol, polydextrose is a polysaccharide composed of randomly crosslinked glucose units with all types of glucosidic bonds (1,6-bonds predominate) containing minor amounts of bound sorbitol. Polydextrose, which is produced using additional processing to improve flavour and colour, is usually used as a sugar- and partial fat-substitute in foods. Polydextrose is not digested but is partially fermented in the large intestine, producing SCFA which are absorbed and utilised. Therefore, polydextrose is widely recognised as yielding an energy value of $4 \cdot 184 \mathrm{~kJ} / \mathrm{g}$. No previous studies have assessed the effect of polydextrose on appetite control.

The aims of the present study were to examine the immediate effects of polydextrose and xylitol, given either alone or in combination, on consumption post-ingestion. The study was also designed to assess the extent to which any satiety-inducing effects would persist after repeated daily dosing for $10 \mathrm{~d}$.

\begin{abstract}
Method
Volunteers

Eight females and eight males were recruited from the student and staff population of the University of Leeds. Volunteers had a mean age and BMI of 30.1 years and $22.7 \mathrm{~kg} / \mathrm{m}^{2}$, respectively, and engaged in regular light exercise. The Three Factor Eating Questionnaire (Stunkard \& Messick, 1985) was used to ensure
\end{abstract}


that all volunteers did not exhibit high levels of dietary restraint. One male subject withdrew for reasons unconnected with the study. As part of a screening procedure, and to compare the sensory characteristics of the experimental yoghurts, a taste test was carried out prior to the start of the study. Volunteers who rated the test materials as less than $50 \mathrm{~mm}$ on a visual analogue pleasantness scale (range $0-100 \mathrm{~mm}$ ) were excluded from the study. All volunteers gave their written consent to take part in the study and ethical approval was granted from the School of Psychology Ethical Committee.

\section{Design}

Volunteers completed four experimental conditions according to a counterbalanced order with each condition separated by a 1-week washout period. During each condition, volunteers were provided with either a control yoghurt $(\mathrm{C})$ or one of three experimental yoghurt formulations (containing xylitol $(\mathrm{X})$, polydextrose $(\mathrm{P})$ or xylitol and polydextrose (XP)) to consume as a snack as part of their normal diet for ten consecutive days. The four conditions differed according to the yoghurt formulation: $\mathrm{C}, 25 \mathrm{~g}$ sucrose/d, no xylitol or polydextrose; X, $25 \mathrm{~g}$ xylitol/d; P, $25 \mathrm{~g}$ polydextrose/ $\mathrm{d}$; and XP, $12.5 \mathrm{~g}$ xylitol/d and $12.5 \mathrm{~g}$ polydextrose $/ \mathrm{d}$. The yoghurts were prepared by Lintech (Reading, UK) and the speciality carbohydrates (xylitol and Litesse ${ }^{\circledR}$ polydextrose) were provided by Danisco Inc. (Ardsley, NY, USA). A strawberry flavoured yoghurt was used as the control yoghurt (\% energy from protein, fat and carbohydrate: 16,14 and 70 , respectively) to which the speciality carbohydrates were added to produce the three experimental yoghurts.

Because the weight of food consumed is a prominent factor that can influence post-ingestive feelings of hunger (Prentice \& Poppitt, 1996), the weight and volume of the yoghurts were held constant. Consequently, the energy content of the yoghurts varied because of the lower energy yield of the speciality carbohydrates. Therefore, the energy content was biased against the three experimental yoghurts in the detection of any satiating action since the control yoghurt contained the most energy (Table 1). Volunteers consumed a standard $200 \mathrm{~g}$ pre-load of yoghurt on each of the ten days. The energy and nutrient content of each of the yoghurts is presented in Table 1 .

\section{Procedure}

Volunteers were instructed to consume one portion of yoghurt at 11.00 hours daily for ten consecutive days. Consumption was monitored via daily records. On days 1 and 10 (test days) volunteers were required to attend the Human Appetite Research Unit

Table 1. Energy and nutrient content for the yoghurt pre-loads (values per $200 \mathrm{~g}$ yoghurt)

\begin{tabular}{lcccc}
\hline & $\mathrm{C}$ & $\mathrm{X}$ & $\mathrm{P}$ & $\mathrm{XP}$ \\
\hline Energy (MJ) & 0.854 & 0.686 & 0.544 & 0.611 \\
Protein (g) & 8.2 & 8.2 & 8.2 & 8.2 \\
Carbohydrate (g) & 35.6 & 35.6 & 35.6 & 35.6 \\
Fat (g) & 3.3 & 3.3 & 3.3 & 3.3 \\
\hline
\end{tabular}

C, control with $25 \mathrm{~g}$ sucrose $/ \mathrm{d}$; X, $25 \mathrm{~g}$ xylitol/d; P, $25 \mathrm{~g}$ polydextrose $/ \mathrm{d} ; \mathrm{XP}, 12.5 \mathrm{~g}$ xylitol/d and $12.5 \mathrm{~g}$ polydextrose $/ \mathrm{d}$. for a fixed breakfast and an ad libitum test lunch. Volunteers attended the Unit at 08.30 hours to be provided with the fixed breakfast. Volunteers were instructed to consume an amount of food similar to their habitual breakfast on the first test day, and this amount was then fixed for each subsequent test day. Therefore, the energy and nutrient content of the breakfast was individually standardised and fixed for each of the four conditions.

Immediately after breakfast volunteers were free to leave the Unit; they were instructed to consume the yoghurt at 11.00 hours and not to consume any other food or drink during the breakfast-lunch interval. At 12.30 hours volunteers returned to the Unit for the ad libitum test lunch and were instructed to eat to a comfortable level of fullness. The food was covertly weighed immediately before and after the test lunch to determine the energy and nutrient content of food consumed. The test lunch was of mixed composition (\% energy from protein, fat and carbohydrate: 16, 31 and 53, respectively) and consisted of a range of sandwiches, crisps and fruit. This test meal was designed to measure energy intake not food selection. The pre-load design is a technique widely used in appetite studies to assess the postingestive effects of varying the characteristics of foods (e.g. energy and macronutrient content) on satiety (Rogers \& Blundell, 1989; Blundell et al. 1993) and in our laboratory the assessment procedures have a sensitivity to detect a variety of manipulations (Green et al. 2000; Lawton et al. 2000; Blundell et al. 2002).

Immediately after the test lunch on day 1 , volunteers were provided with their yoghurts for days 2-9 and were instructed to return at 08.30 hours on day 10 . During test days 1 and 10 only, subjective ratings of hunger and fullness were periodically monitored using the Electronic Appetite Ratings System. This is a relatively new electronic method of using visual analogue scales to measure subjective states; the procedure has been described previously (King et al. 1997) and has been fully validated (Delargy et al. 1996; Stubbs et al. 2001). Visual analogue scales have been used previously in appetite studies and have been shown to be sensitive to many manipulations (Hill \& Blundell, 1986). Volunteers completed the subjective ratings immediately before and after food consumption (i.e. breakfast, yoghurt and test lunch) and at hourly intervals between the meals.

On days 2-9 (free-living) volunteers were not required to visit the Unit, but were instructed to consume the yoghurt pre-load at the same time of the day (11.00 hours) and to record this consumption. This recording was instituted in order to ensure compliance with the instructions. At the debriefing session at the end of the study, all volunteers confirmed that all test yoghurts had been consumed. On days 1 and 10 volunteers recorded experiences of bloatedness and nausea by completing visual analogue scales in an end-of-day questionnaire before retiring to bed.

\section{Statistical analysis}

SPSS (Windows version 9.0; SPSS Inc., Chicago, IL, USA) was used to perform inferential analysis on the data. A one-way ANOVA was used to compare differences between the test yoghurts for perceptions of taste at screening. ANOVA was used to compare the yoghurts $\mathrm{C}, \mathrm{X}, \mathrm{P}$ and $\mathrm{XP}$, where the hierarchical structure of the experiment, with days within conditions within subjects, and different factors for each level was accounted for. Each main effect and interaction was tested against the appropriate residual (sex at subject level, treatment at condition level and days within condition). A two-way ANOVA was used to 
compare the differences in change in hunger and fullness between the yoghurts immediately after consumption and for the test lunch energy intakes (condition and day as the repeated measures).

Bonferroni corrections were used where necessary. Since multiple comparisons were made, a probability of $0.0167(0 \cdot 05 / 3)$ was considered as statistically significant. The control served as the placebo condition and did not include xylitol or polydextrose; hence all three experimental conditions (X, P and XP) were compared with $\mathrm{C}$.

\section{Results}

\section{Palatability}

All volunteers completed a taste test before starting the study. The results showed that although yoghurts $\mathrm{X}$ and $\mathrm{P}$ were rated as slightly more palatable ( 65.6 and $64.8 \mathrm{~mm}$, respectively) than yoghurts $\mathrm{C}$ and XP (62.6 and $62.5 \mathrm{~mm}$, respectively), there was no significant difference $(F(3,39)=0 \cdot 16, P=0 \cdot 92)$.

\section{Ad libitum test lunch}

The suppression of energy intake exerted by the experimental yoghurts was calculated by subtracting the test lunch energy intake following ingestion of each of the experimental yoghurts from the test lunch energy intake following ingestion of the control yoghurt. The three experimental yoghurts exerted a suppression of energy intake compared with the control yoghurt (Table 2). The difference in energy intake between the conditions was not significant $(F(3,39)=2 \cdot 66, P=0 \cdot 06)$. The pooled, mean suppression (mean of days 1 and 10) induced by the $\mathrm{X}, \mathrm{P}$ and $\mathrm{XP}$ yoghurts compared with $\mathrm{C}$ were $11.9 \% \quad(0.37 \mathrm{MJ}), 9.9 \%$ $(0.31 \mathrm{MJ})$ and $7.2 \%(0.22 \mathrm{MJ})$, respectively. There was no significant main effect of day $(F(1,13)=0 \cdot 33, P=0.58)$. The males consumed significantly more energy than the females across all conditions $(F(1,13)=6 \cdot 11, P=0 \cdot 03)$. There were no significant interactions between condition and day, gender and day, gender and condition, and between condition, day and gender (highest $F(3,39)=0 \cdot 87, P=0 \cdot 46)$.

As the yoghurt pre-loads varied in energy content, with the satiety-inducing energy effect biased in favour of the control yoghurt, the analysis was repeated using the combined (yoghurt pre-load and test lunch) energy intake. When the energy differential of the yoghurt pre-loads was accounted for, the suppression of energy intake at the test meal was accentuated and statistically significant (Fig. 1). There was a highly significant difference in combined (net) energy intake between the four conditions
$(F(3,39)=7 \cdot 40, P<0 \cdot 001)$. Using Bonferroni corrections, the difference in energy intake between $\mathrm{P}$ and $\mathrm{C}$ was statistically significant (mean difference: 0.63 MJ, $P=0.002$ ). However, the difference between $\mathrm{X}$ and $\mathrm{C}$ approached significance (mean difference: $0.55 \mathrm{MJ}, P=0.017$ ). The mean suppression in energy intake induced by the experimental yoghurts $(\mathrm{X}-\mathrm{C}, \mathrm{P}-\mathrm{C}$ and $\mathrm{XP}-\mathrm{C}$ ), calculated using the pooled means (mean of days 1 and 10 for each condition), were $0.55,0.63$ and $0.39 \mathrm{MJ}$, respectively.

Similar to the test lunch intakes without the pre-load included, there was a significant effect of gender $(F(1,13)=6 \cdot 11, P=0 \cdot 03)$. There was no significant main effect of day $(F(1,13)=0.33$, $P=0.58$ ), or significant interactions between day and gender, gender and condition, day and condition, or between condition, day and gender (highest $F(3,39)=0 \cdot 87, P=0.46$ ).

\section{Subjective motivation to eat}

Volunteers rated their subjective states immediately before and immediately after consumption of the yoghurt on days 1 and 10 ; therefore it was possible to compare the acute satiating effect by assessing the suppression of hunger, or increase in fullness, of the four yoghurts. ANOVA revealed that there was a significant difference in the effect on satiety between the yoghurts for fullness $(F(3,39)=4.00, \quad P=0.015)$ but not for hunger (Fig. 2). Bonferroni corrections demonstrated that there was a significant difference in the effect on satiety (fullness) only between $\mathrm{C}$ and XP (mean difference: $13.0 \mathrm{~mm}, P=0.003$ ). There was no significant difference between the males and females $(F(1,13)=0.80, \quad P=0.39) \quad$ or a main effect of day $(F(1,13)=1 \cdot 86, P=0 \cdot 20)$. There were no significant interactions between day and gender, day and condition, gender and condition, or between condition, day and gender (highest $F(1,13)=1 \cdot 35$, $P=0 \cdot 27$ ).

A 'relative' satiating effect was calculated to account for the differential in energy content between the yoghurt formulations. This was calculated by dividing the suppression (post-consumption to pre-lunch interval) of hunger by the energy content $(\mathrm{kJ})$ of each yoghurt. When the energy differential between the yoghurts was accounted for, ANOVA revealed that there was a significant effect of yoghurt condition on the effect on 'relative' satiety for fullness only $(F(3,39)=6 \cdot 23, P=0 \cdot 002)$. Again, Bonferroni corrections showed that the only significant difference was between $\mathrm{C}$ and XP (mean difference: $0 \cdot 1 \mathrm{~mm} / \mathrm{kJ}, P<0 \cdot 001$ ). There were no significant main effects of day or gender (highest

Table 2. Energy intake (MJ) during the ad libitum test lunch following consumption of the yoghurts

(Mean values with their standard deviation)

\begin{tabular}{|c|c|c|c|c|c|c|c|c|c|c|c|c|c|c|c|c|}
\hline & \multicolumn{4}{|c|}{ C } & \multicolumn{4}{|c|}{$x$} & \multicolumn{4}{|c|}{$\mathrm{P}$} & \multicolumn{4}{|c|}{$\mathrm{XP}$} \\
\hline & \multicolumn{2}{|c|}{ Day 1} & \multicolumn{2}{|c|}{ Day 10} & \multicolumn{2}{|c|}{ Day 1} & \multicolumn{2}{|c|}{ Day 10} & \multicolumn{2}{|c|}{ Day 1} & \multicolumn{2}{|c|}{ Day 10} & \multicolumn{2}{|c|}{ Day 1} & \multicolumn{2}{|c|}{ Day 10} \\
\hline All & 3.03 & 1.09 & 3.20 & 0.75 & $2 \cdot 71$ & 0.83 & $2 \cdot 80$ & 0.97 & 2.85 & 0.94 & 2.77 & 0.87 & $2 \cdot 89$ & 0.84 & 2.90 & 1.06 \\
\hline Females & $2 \cdot 46$ & 0.90 & $2 \cdot 69$ & 0.68 & $2 \cdot 49$ & 1.00 & $2 \cdot 33$ & 1.08 & 2.49 & 0.80 & 2.48 & 0.90 & 2.52 & 0.95 & 2.42 & 1.09 \\
\hline Males & 3.69 & 0.94 & 3.72 & 0.36 & 2.97 & 0.54 & 3.30 & 0.50 & $3 \cdot 26$ & 0.98 & 3.09 & 0.77 & $3 \cdot 30$ & 0.46 & 3.46 & 0.75 \\
\hline
\end{tabular}

C, control with $25 \mathrm{~g}$ sucrose $/ \mathrm{d} ; \mathrm{X}, 25 \mathrm{~g}$ xylitol/d; $\mathrm{P}, 25 \mathrm{~g}$ polydextrose $/ \mathrm{d} ; \mathrm{XP}, 12.5 \mathrm{~g}$ xylitol $/ \mathrm{d}$ and $12.5 \mathrm{~g}$ polydextrose $/ \mathrm{d}$.

Males consumed significantly more energy than females across all conditions $(P=0.03)$. 


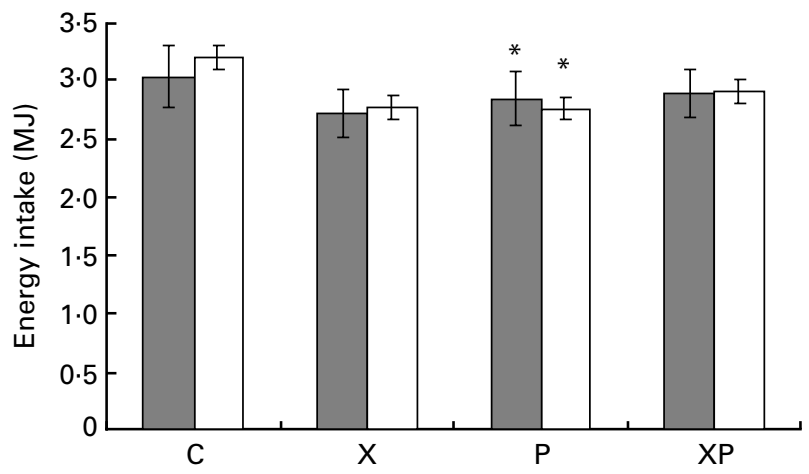

Fig. 1. Energy intakes at test lunch on day $1(\square)$ and day $10(\square)$ following consumption of the yoghurts (C, control with $25 \mathrm{~g}$ sucrose $/ \mathrm{d} ; \mathrm{X}, 25 \mathrm{~g}$ xylitol/d; $\mathrm{P}, 25 \mathrm{~g}$ polydextrose $/ \mathrm{d} ; \mathrm{XP}, 12.5 \mathrm{~g}$ xylitol/d and $12.5 \mathrm{~g}$ polydextrose/d). Values are means with standard error shown by vertical bars. Mean values were significantly different from those of the control condition using Bonferroni correction: ${ }^{*} P=0.002$.

$F(1,13)=2 \cdot 28, P=0 \cdot 16$ ) or any significant interactions (highest $F(1,13)=1 \cdot 52, P=0 \cdot 24)$.

The end-of-day questionnaire did not reveal any significant differences between the four conditions in self-reports of bloatedness or nausea (highest $F(3,39)=1 \cdot 01, P=0 \cdot 40$ ). There was no significant main effect of day $(F(1,13)=0.04, P=0.84)$ or any significant interactions highest $F(3,13)=2 \cdot 40, P=0 \cdot 15)$. The mean scores for bloatedness and nausea are presented in Table 3.

\section{Discussion}

The results of the present study have demonstrated that there is a tendency for xylitol and polydextrose to exert a mild satiating effect, reflected in decreased subjective motivation to eat and food intake. However, for the suppression in food intake, this effect was statistically significant only for polydextrose compared with the control, and only when the energy difference between the yoghurt pre-loads was accounted for. However, there was some indication that the three experimental yoghurts exerted differential effects on satiety. First, the xylitol-polydextrose combination exerted more of a satiating effect (reflected in subjective ratings of fullness) than did xylitol and polydextrose independently.

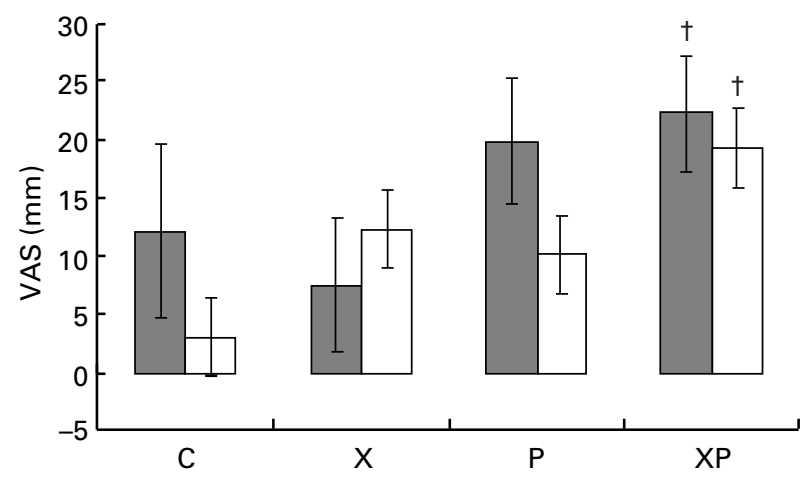

Fig. 2. Elevation in fullness ( $m m$ on a visual analogue scale (VAS)) for all subjects immediately following consumption of the yoghurts (C, control with $25 \mathrm{~g}$ sucrose $/ \mathrm{d}$; X, $25 \mathrm{~g}$ xylitol/d; P, $25 \mathrm{~g}$ polydextrose $/ \mathrm{d}$; $X \mathrm{P}, 12.5 \mathrm{~g}$ xylitol/d and $12.5 \mathrm{~g}$ polydextrose/d) on day $1(\square)$ and day $10(\square)$. Values are means with standard error shown by vertical bars. Mean values were significantly different from those of the control condition using Bonferroni correction: $\dagger P=0.003$.
Table 3. Scores for self-reports of nausea and bloatedness

\begin{tabular}{|c|c|c|c|c|}
\hline & & Mean & SD & Range \\
\hline \multicolumn{5}{|c|}{ Nausea } \\
\hline \multirow[t]{2}{*}{ C } & Day 1 & $28 \cdot 8$ & 14.9 & $0-50$ \\
\hline & Day 10 & $26 \cdot 0$ & $17 \cdot 6$ & $0-69$ \\
\hline \multirow[t]{2}{*}{$x$} & Day 1 & $23 \cdot 8$ & $14 \cdot 0$ & $0-61$ \\
\hline & Day 10 & 23.0 & $13 \cdot 0$ & $0-47$ \\
\hline \multirow[t]{2}{*}{$\mathrm{P}$} & Day 1 & $20 \cdot 6$ & $14 \cdot 0$ & $0-47$ \\
\hline & Day 10 & $24 \cdot 6$ & $19 \cdot 5$ & $0-63$ \\
\hline \multirow[t]{2}{*}{$\mathrm{XP}$} & Day 1 & 23.8 & $15 \cdot 6$ & $0-54$ \\
\hline & Day 10 & $25 \cdot 0$ & $15 \cdot 7$ & $0-52$ \\
\hline \multicolumn{5}{|c|}{ Bloatedness } \\
\hline \multirow[t]{2}{*}{ C } & Day 1 & $43 \cdot 7$ & $13 \cdot 2$ & $20-64$ \\
\hline & Day 10 & $40 \cdot 2$ & 14.4 & $16-60$ \\
\hline \multirow[t]{2}{*}{$x$} & Day 1 & $39 \cdot 2$ & 14.4 & $9-59$ \\
\hline & Day 10 & 39.5 & $13 \cdot 3$ & $20-59$ \\
\hline \multirow[t]{2}{*}{$P$} & Day 1 & $34 \cdot 1$ & $16 \cdot 2$ & $5-60$ \\
\hline & Day 10 & $42 \cdot 5$ & $19 \cdot 6$ & $11-77$ \\
\hline \multirow[t]{2}{*}{$\mathrm{XP}$} & Day 1 & $37 \cdot 7$ & $15 \cdot 5$ & $15-59$ \\
\hline & Day 10 & $37 \cdot 7$ & $14 \cdot 8$ & $5-54$ \\
\hline
\end{tabular}

C, control with $25 \mathrm{~g}$ sucrose $/ \mathrm{d} ; \mathrm{X}, 25 \mathrm{~g}$ xylitol/d; $\mathrm{P}, 25 \mathrm{~g}$ polydextrose $/ \mathrm{d} ; \mathrm{XP}, 12.5 \mathrm{~g}$ xylitol/d and $12.5 \mathrm{~g}$ polydextrose $/ \mathrm{d}$.

Second, the yoghurt containing polydextrose on its own was the only formulation to significantly suppress food intake (compared with the control) when the differential in energy content of the pre-loads was taken into account. However, for the yoghurt containing xylitol on its own, the effect approached significance. The inclusion of the energy content of the pre-load in the analysis is justified and has important implications for the possible use of these materials in appetite control. The energy content of a preload is known to be the most important feature for generating satiety (Prentice \& Poppitt, 1996). Foods containing less energy would usually be expected to have less of a satiating effect than higher energy foods of similar weight, volume and taste. The reduced energy content of the experimental yoghurts (compared with the placebo control), together with their post-ingestive suppressive effects on appetite, could be of benefit to individuals aiming to reduce overall energy intake to promote a negative energy balance. The energy of the yoghurt pre-loads varied because we decided to fix the other characteristics (i.e. weight and volume) to prevent these parameters exerting different satiety-inducing effects. Therefore, we tailored the energy loads so that the control yoghurt had the highest energy content; in principle, this should have provided the control yoghurt with the greatest satiating potential. Thus the design was particularly challenging, requiring the speciality carbohydrates both to resist any compensation for their reduced caloric value and to demonstrate a reduction in test meal food intake in order to demonstrate a further satiating effect. Because of their lower energy content, the formulation yoghurts would have been expected to exert a weaker effect on satiety via this mechanism; in fact, the experimental yoghurts exerted a somewhat greater effect than the control yoghurt and this effect must be due to mechanisms influencing satiety signals.

However, we do not suggest that the appetite system would be sensitive to the small differentials in energy content between the yoghurt pre-loads. Therefore, it is recognised that the overall effects of these substances on appetite control is a result of a reduced energy content coupled with a mild increase in postingestive satiety. 
The suppression of food intake at the test meal (without the pre-load energy accounted for) was approximately $10 \%$, which could allow people, acting judiciously, to use xylitol and/or polydextrose to reduce meal size. For an individual habitually consuming a lunch of $2510-3347 \mathrm{~kJ}$, a $300 \mathrm{~kJ}$ daily reduction in food intake (assuming no compensation later) would result in a weight loss of $1 \mathrm{~kg}$ in approximately 4 months (Elia \& Livesey, 1992). Therefore, xylitol and polydextrose can be considered as food agents capable of reducing food intake with the possibility of leading to weight reduction. However, an effect on body weight has not been demonstrated. The volunteers in this study followed the protocol only for $10 \mathrm{~d}$ and a long-term weight loss trial is required before any firm implications can be made about weight loss. However, the effect of the material used in this study endured well beyond a single dosing.

The present investigation has confirmed the results of a previous study (TC Lambert, unpublished results) demonstrating that consumption of a polydextrose pre-load reduces food intake at a subsequent meal. Although no published data exist for polydextrose, the present results indicate that it is also a substance capable of suppressing food intake. Its lower energy density $(\mathrm{kJ} / \mathrm{g})$ is of added value, and indicates that such a material could impact on appetite control through two separate mechanisms. However, the effect exerted by the experimental yoghurts was not simply due to their lower energy values, but also to an independent post-ingestive effect via some satiety signalling pathway. This pre-load design was sensitive enough to detect suppression in intake even with a small dose $(25 \mathrm{~g})$ of the speciality carbohydrate in a single load. The scope of the experiment did not permit an investigation of potential mechanisms. However, a capacity to delay gastric emptying (preserving gastric distension) or adjusting the post-ingestive profile of blood glucose or insulin could be the causes of, or at least biomarkers of, the measured effects on appetite. It is also unlikely that there is a glucostatic mechanism involved because of the very low glycaemic index values of xylitol and polydextrose (Foster-Powell et al. 2002). There was no significant difference in self-report of negative symptoms (e.g. bloatedness and nausea) between the conditions and none of the volunteers reported experiencing problems when given the opportunity on the debriefing form. Therefore, it is unlikely that the suppression of food intake could be related to gastric discomfort or nausea.

Since there is current considerable interest in developing food materials for incorporation into nutraceuticals or functional foods for appetite control, it is important to evaluate products such as xylitol and polydextrose that have the potential to yield a beneficial restraining action. The present study has demonstrated a mild but clear effect of xylitol and polydextrose taking place via two separate mechanisms. The energy reduction brought about is unlikely to engender a major reduction in body weight but could contribute to preventing weight gain or regain. In various initiations to combat the obesity epidemic it is likely that an effective impact will result from a large number of small adjustments in the eating repertoire and the food environment. Increasing the number of products with a modulating effect on appetite could contribute, possibly to a considerable extent in some individuals.
In conclusion, xylitol and polydextrose could be useful products due to their lower delivery of energy coupled with the mild increase in satiety. The results of the present study will enable researchers to evaluate whether xylitol and polydextrose have a sufficiently powerful effect to play a role in this area.

\section{Acknowledgements}

Part of these data was presented at the 10th European Congress on Obesity held in Helsinki, Finland, on 29-31 May 2003.

\section{References}

Blundell JE, Burley VJ, Cotton JR \& Lawton CL (1993) Dietary fat and the control of energy intake: evaluating the effects of fat on meal size and postmeal satiety. Am J Clin Nutr 57, 772S-778S.

Blundell JE, Cooling J \& King NA (2002) Differences in postprandial responses to fat and carbohydrate loads in habitual high and low fat consumers (phenotypes). Br J Nutr 88, 125-132.

Delargy HJ, Lawton CL, Smith FC, King NA \& Blundell JE (1996) Electronic Appetite Rating System (EARS): validation of continuous automated monitoring of motivation to eat. Int J Obes 20, Suppl. 4, 104.

Elia M \& Livesey G (1992) Energy expenditure and fuel selection in biological systems. World Rev Nutr Diet 70, 68-131.

Foster-Powell K, Holt SHA \& Brand-Miller JC (2002) International table of glycemic index and glycemic load values: 2002. Am J Clin Nutr 76, $5-56$.

Green SM, Wales JK, Lawton CL \& Blundell JE (2000) Comparison of high-fat and high-carbohydrate foods in a meal or snack on shortterm fat and energy intakes in obese women. Br J Nutr 84, 521-530.

Hill AJ \& Blundell JE (1986) Macronutrients and satiety: the effects of high carbohydrate and high protein meals on subjective motivation to eat and preferences. Nutr Behav 3, 133-144.

King NA, Lluch A, Stubbs RJ \& Blundell JE (1997) High dose exercise does not increase hunger or energy intake in free living males. Eur $J$ Clin Nutr 51, 478-483.

Lawton CL, Delargy HJ, Brockman J, Smith FC \& Blundell JE (2000) The degree of saturation of fatty acids influences post-ingestive satiety. $\mathrm{Br} J$ Nutr 83, 473-482.

Prentice AM \& Poppitt SD (1996) Importance of energy density and macronutrients in the regulation of energy intake. Int J Obes Relat Metab Disord 20, S18-S23.

Rogers PJ \& Blundell JE (1989) Separating the actions of sweetness and calories: effects of saccharin and carbohydrates on hunger and food intake in human subjects. Physiol Behav 45, 1093-1099.

Salminen EK, Salminen SJ, Porkka L, Kwasowski P, Marks V \& Koivistoinen PE (1989) Xylitol vs glucose: effect on the rate of gastric emptying and motilin, insulin, and gastric inhibitory polypeptide release. Am J Clin Nutr 49, 1228-1232.

Shafer RB, Levine AS, Marlette JM \& Morley JE (1987) Effects of xylitol on gastric emptying and food intake. Am J Clin Nutr 45, 744-747.

Stubbs RJ, Hughes DA, Johnstone AM, Rowley E, Ferris S, Elia M, Stratton RJ, King NA \& Blundell JE (2001) Description and evaluation of a Newton-based electronic appetite rating system for temporal tracking of appetite in human subjects. Physiol Behav 72, 615-619.

Stunkard AJ \& Messick S (1985) The three factor eating questionnaire to measure dietary restraint, disinhibition and hunger. J Psychosom Res 29, 71-83. 